\title{
SOCIAL WELFARE LOSS DUE TO SECOND-BEST PRICING: an application to the Portuguese Telecommunications
}

\author{
Maria Lurdes Castro Martins* \\ Departamento de Economia, Escola de Economia e Gestão \\ Universidade do Minho, Campus de Gualtar, 4710 Braga, Portugal \\ Tel: +351253 604510. Fax: +351253676375 \\ Imartins@eeg.uminho.pt
}

\begin{abstract}
The Telecommunications industry is usually characterised by low marginal costs and significant fixed costs which are the conditions for the inefficiency of marginal cost pricing. In such cases theory postulates that optimal pricing is obtained by maximising welfare subject to a restriction of viability of the firm: the second-best pricing scheme. The possible Welfare Losses due to second-best pricing varies according to the values of marginal costs, prices and demand elasticities. In this paper we intend to analyse to what extent the second-best pricing has been achieved in the Portuguese Telecommunications firm CTT, over the period 1950-1984 as well as the magnitude of the price-cost margins and Welfare Losses created. We obtained empirical evidence of the presence of economies of scale, a Welfare Loss estimate of $1 \%$ of the Telecommunications receipts and a result that price was $40 \%$ greater than marginal cost. We concluded that price regulation and public ownership of the firm did not seriously affect social welfare over the sample period (it should be noted that it is the non-digital and fixed-wire infrastructure period). Therefore, it is important to study the impact of new digital and non-wire technologies and new services provided in the old regulatory scenery.
\end{abstract}

Key Words: Telecommunications; Natural Monopoly; Monopoly Welfare Loss; Second-best Pricing; Regulation.

JEL Classification: L96; L51; D42; D60 


\section{Introduction}

Over the past decade many changes have occurred in the telecommunications industry all over the world. These changes led several authors to investigate the issue of telecommunications regulatory reform with particular emphasis on the question of why should government interfere and in what conditions. The economic literature, as surveyed by Braeutigam (1989), points out two conditions that justify regulatory intervention in an industry: the existence of a natural monopoly and an important Social Welfare Loss due to "second-best" pricing.

An industry is considered a natural monopoly if in any relevant range of the output, a single firm in the market achieves a lower unit cost of production than two or more competitors (Baumol, 1982). In such a case competition leads to an inefficient production structure, because prices are set higher and less demand is satisfied. Given its relatively small marginal costs and important positive fixed costs, significant economies of scale are present in the telecommunications industry.

If the firm must charge a uniform tariff and the net economic benefit is measured by the sum of producer plus consumer surplus, economic theory states that optimal price is achieved when the service is provided to all customers who are willing to pay at least as much as the marginal cost of production. However, in the natural monopoly case this would entail a negative level of profits. The solution to the welfare maximisation question, subject to a viability constraint, leads to the "second-best" pricing ${ }^{1}$ solution. At this price level there is a "dead-weight loss" which can be measured by the sum of the variations in the consumer and producer surpluses. Willig 
(1976) has studied the robustness of this measure to the underlying assumptions $^{2}$ and found it to be quite reliable. Notwithstanding the recent contributions of Aiginger and Pfaffermayr (1997) this has become the established method to measure the Welfare Loss of a monopoly.

It is this study's intention to analyse the extent to which this secondbest pricing has been achieved in the Portuguese telecommunications industry for the period of $1950-1984$. To accomplish this aim information on the largest Portuguese telecommunications enterprise is used ${ }^{3}$.

Cabral (1990) studied a related but different issue. He estimated the optimal pricing for the Portuguese telephone service, that is, the price structure that maximises an "adjusted Social Welfare" function ${ }^{4}$. Other authors like $\mathrm{Ng}$ and Weisser (1974), Feldestein (1972) and Schmalansee (1981) developed their work finding optimal second-best pricing schemes using a methodology similar to that Cabral adopted. The methodology used here differs from Cabral's model in several aspects. First, specifically the technology of the firm is studied by estimating a Translog cost function. Second, the usage charge is utilized instead of the two-part tariff, as in Gabel and Kennet (1993). Finally, in the Social Welfare function consumer and producer surpluses with equal weights are included, and distribution effects are not taken into account ${ }^{5}$.

The methodology adopted here follows that used by Braeutigam (1989) to decide when to regulate a natural monopoly. The paper is organised as follows: Section 2 presents the model used to estimate the price-cost margins and the Welfare Loss in the Portuguese telecommunications industry. Section 3 describes the data and estimation 
procedures used. Section 4 presents the empirical results obtained. Finally, section 5 concludes with a discussion of the findings and their significance to the Portuguese Telecommunications deregulation issue.

\section{Methodological Issues}

Marginal costs, prices and elasticity of demand influence the possible Welfare Loss. As some recent studies did (Kim, 1995) this study begins by obtaining a marginal cost measure using the estimation of a Translog Cost Function, which is a very flexible function because it is obtained as a second order approximation to any cost function. The Translog Cost Function that we used has one variable for output ${ }^{6}$ and three variables as inputs: capital, materials and labour and one variable for the technical progress.

Once the symmetry and homogeneity restrictions are imposed $(\text { Greene, 1997 })^{7}$ this function can be written as:

$$
\begin{aligned}
& \log \frac{T C}{p_{m}}=a+\sum_{i=1}^{2} b_{i} \log \frac{p_{i}}{p_{m}}+d_{1} \log t+a_{1} Y^{*}+ \\
& +\frac{1}{2} a_{11} Y^{* 2}+\frac{1}{2} d_{11}(\log t)^{2}+\frac{1}{2} \sum_{i=1}^{2} \sum b_{i j} \log \frac{p_{i}}{p_{m}} \log \frac{p_{j}}{p_{m}}+ \\
& +\sum_{i=1}^{2} c_{1 i} Y^{*} \log \frac{p_{i}}{p_{m}}+\sum_{i=1}^{2} f_{1 i} \log t \log \frac{p_{i}}{p_{m}}+e_{11} Y^{*} \log t
\end{aligned}
$$

with the following share equations: 


$$
\begin{aligned}
& \mathrm{s}_{1}=\mathrm{b}_{1}+\sum_{\mathrm{i}=1}^{2} \mathrm{~b}_{1 \mathrm{i}} \log \frac{\mathrm{p}_{\mathrm{i}}}{\mathrm{p}_{\mathrm{m}}}+\mathrm{c}_{11} \mathrm{Y}^{*}+\mathrm{f}_{11} \log \mathrm{t} \\
& \mathrm{s}_{2}=\mathrm{b}_{2}+\sum_{\mathrm{i}=1}^{2} \mathrm{~b}_{\mathrm{i} 2} \log \frac{\mathrm{p}_{\mathrm{i}}}{\mathrm{p}_{\mathrm{m}}}+\mathrm{c}_{12} \mathrm{Y}^{*}+\mathrm{f}_{12} \log \mathrm{t}
\end{aligned}
$$

where $t$ is the technical progress; $\mathrm{Y}^{*}$ is the "Box-Cox" ${ }^{8}$ transformation of the output variable, $\mathrm{p}_{\mathrm{i}}$ is the price of factor $i, \mathrm{~s}_{\mathrm{i}}$ is the share of factor $\mathrm{i}$ on total costs TC, with $i$ representing labour $(i=1)$, capital $(i=2)$ or materials $(i=3)$.

From the Translog function, the cost elasticity of output is derived:

$$
\frac{\partial \log T C}{\partial \log Y}=Y^{\lambda}\left(a_{1}+a_{11} Y^{*}+c_{11} \log \frac{p_{1}}{p_{m}}+c_{12} \log \frac{p_{2}}{p_{m}}+e_{11} \log t\right),
$$

which evaluated at the "expansion point" takes the following form:

$$
\frac{\partial \log \mathrm{TC}}{\partial \log \mathrm{Y}}=\mathrm{a}_{1} .
$$

Scale economies can be calculated as the inverse of $a_{1}$, and marginal costs as,

$$
\mathrm{MC}=\frac{\mathrm{TC}}{\mathrm{Y}} \frac{\partial \log \mathrm{TC}}{\partial \log \mathrm{Y}}=\mathrm{a}_{1} \frac{\mathrm{TC}}{\mathrm{Y}} .
$$

Finally, the Welfare Loss can be measured by the "dead-weight loss triangle" given by the equation ${ }^{10}$ :

$$
W L=\frac{1}{2} \varepsilon \frac{(P-M C)^{2}}{P} Y
$$


where $\varepsilon$ is the price elasticity of telecommunication services.

\section{Data and Estimation Procedures.}

The methodology followed here, in relation to the Portuguese telecommunications industry, is subject to an important limitation. We know that the telecommunications system offers a wide range of services such as the connection and use of telephone lines, private circuits rental, leased lines, transmission capacity, telex, and others. However, the available

Portuguese data are very poor, forcing us to use a single measure of output, namely the real service receipts.

This study opted to work with data spanning from 1950 to 1984 since after the mid-eighties digital technology was introduced in the Portuguese Telecommunications infrastructures. This technology has led to substantial changes in the cost structure of industry. Moreover, in the mid 1980s, with the advent of the information society many new products were introduced (mobile phones, fax) which could have changed demand conditions considerably.

The capital measure was built using the investment, the capital stock, the depreciation and the price of investment. The price of capital is the ratio of capital expenditures and the stock of capital. The labour variable is approximated by a measure of the number of working hours and the price of labour is the ratio of labour expenditures and the number of working hours. Materials are the material expenditures and their price is an index of the 
most important materials consumed. Technical progress values are the percentage, at the local loop, of the automatic telephone stations.

The translog function and the two share equations were jointly estimated as Seemingly Unrelated Regression equations (SURE) ${ }^{11}$. To prevent the singularity of the variance-covariance matrix we deleted the materials share equation. The maximum likelihood parameter estimates obtained are the result of the iterative Zellner ${ }^{12}$ efficient estimation method. This method is more efficient than OLS the greater is the correlation between the disturbance terms from different equations and the lesser is the correlation between dependent variables.

\section{Empirical Results}

The results for the estimation of the Translog cost function are shown in Table I. In general all parameter estimates have the expected sign and statistical tests seem to ensure that variables are statiscally significant.

[ INSERT TABLE I ]

Following the methodology presented in Section II, we present in Table II some estimates based on the translog Cost function.

[ INSERT TABLE II]

The estimated value for the scale economies at the approximation point 1.84 , is very close to what Kiss et al. (1983) estimated for Bell Canada (1.75) and well within the range of values found by other authors for 
telecommunications enterprises in the United States and Canada (1.42 to 2.28) as surveyed by Kiss et al. (1987).

To determine the Welfare Loss, the published price elasticities estimated by Pereira (1991) for the period 1968-1988 were used. It was assumed that these results are also valid for a longer period. The usage price elasticities selected ranged from -0.064 to $-0.1596^{13}$. The results show a Welfare Loss ranging from $0.0972 \%$ to $0.6042 \%$, according to the value used for the demand elasticity. This is, as Brauetigam (1989) put it, a "very tolerable" loss.

Despite the small Welfare Loss, it seems that prices are set in a way that takes into account the survival of the firm. The estimated cost margin for this period is $40.631 \%$, close to Rohlf's (1979) estimate of $50 \%$ for local services. The results also suggest that prices are set close to the secondbest solution estimated by Cabral (1990) (price-cost of access margin of $100 \%$ and price-cost of use margin of $25 \%$ ).

\section{Conclusion}

As Seabra (1993) and others, this study found some evidence that the market for Portuguese telecommunications was a natural monopoly. Our estimates are a rough approximation to the subadditivity issue, because a single variable was used as output and the telecommunications market is greatly represented by multi-product firms. Nevertheless we can conclude that the production of telephone service with the fixed-wire technology, over this period, 1950-1984, exhibits a strong level of scale economies. And this is the sufficient condition for the existence of a single output natural monopoly. 
The main issue in this paper was not the existence of a natural monopoly but the estimate of the relative magnitude of the welfare loss due to the price behaviour of the telecommunications firm studied. Thus, a positive analysis of the welfare implications of the specific regulatory environment was followed, prevailing on the Portuguese telecommunications market. The Portuguese telecommunications firm was publicly owned. A positive profit of the firm could be assumed as a substitute to government taxation $^{14}$. The price-cost margin estimate obtained was not significantly different from second-best optimal estimates. The welfare loss generated seemed to be very "tolerable".

The main result seems to be that the price regulation and the public ownership of this Portuguese telecommunications firm did not seriously affect social welfare over our sample period.

It should finally be noted that the analysis of this paper refers to the non-digital technology period and our conclusions must be indubitably associated with this. Therefore, an important task for further work is to study the impact of new digital and non-wire technologies and new services provided on the old regulatory environment.

\section{Acknowledgements:}

Comments on an earlier draft by Vasconcellos, Paulo Guimarães and the participants of a departmental seminar at the University of Minho were very helpful. Remaining error is mine. Suggestions are invited. 


\section{References:}

Aiginger, Karl and Pfaffermayr, Michael (1997) Looking at the cost side of "monopoly", The Journal of Industrial Economics, 45, 245-267.

Baumol, J.William (1982) Contestable markets:An uprising in the theory of industry structure, The American Economic Review, 72, 1-15.

Baumol, J.William and Bradford, David (1970) Optimal departures from marginal cost pricing, The American Economic Review, 60, 265-283.

Baumol, J.William; Panzar, J.C. and Willig, R.D. (1982) Contestable markets and the theory of industry structure, Harcourt Brace Jovanovitch, New York.

Braeutigam, Ronald (1989) Optimal policies for natural monopolies, in Handbook of Industrial Organization (Ed.) Richard Schmalensee and Robert Willig, North-Holland, Amsterdam, pp. 1289-1346.

Brock, Gerald W. (1994) Telecommunications Policy for the Information Age: From Monopoly to Competition, Harvard University Press, London.

Cabral, Luís M. (1990) Optimal pricing of the Portuguese telephone service, Applied Economics, 22, 211-220.

Demsetz, H. (1968) Why regulate utilities?, Journal of Law and Economics, 11, 55-65.

Feldstein, M.S. (1972) Equity and efficiency in public pricing: the optimal two-part tariff, Quarterly Journal of Economics, 80, 175-187.

Gabel, D. and Kennet (1993) Pricing of Telecommunications Services, Review of Industrial Organization, 8, 1-14. 
Greene, William (1997) Econometric Analysis, Prentice-Hall International, New Jersey.

Kim, Youn H. (1995) Marginal Cost and Second-Best Pricing for Water Services, Review of Industrial Organization, 10, 323-338.

Kiss, Ferenc and Lefebvre, Bernard (1987) Econometric models of Telecommunications firms - a survey, Revue Economique, 2, 307-374.

Mas-Collel, Andreu; Whinston, Michael and Green, Jerry (1995) Elements of Welfare Economics and Axiomatic Bargaining in Microeconomic Theory, Oxford University Press, London.

Mitchell, Bridger (1978) Optimal pricing of local telephone service, American Economic Review, 68, 517-537.

Mitchell, Bridger and Vogelsang, Ingo (1991) Telecommunications pricing-theory and practice, Cambridge University Press, New York.

Morris, Derek J. and Hay, Donald A. (1991) Industrial Economics and Organization: Theory and Evidence, Oxford University Press, London.

Ng,Y.K. and Weissner,M. (1974) Optimal pricing with a budget constraint-the case of the two-part tariff, Review of Economic Studies, 41, $337-345$.

Pereira, Pedro Telhado (1991) Telephone Demand: A theoretical approach and its application to the Portuguese case, Working Paper 175, Universidade Nova de Lisboa.

Rohlfs, J.H. (1979) Economically efficient Bell system pricing, Discussion Paper, Bell Laboratories.

Schmalansee, R. (1981) Monopolistic two-part pricing arrangement, Bell Journal of Economics, 12, 445-466. 
Seabra, M.Carmo (1993) Natural Monopoly in Portuguese telecommunications, Applied Economics, 25, 489-494.

Willig, R.D. (1976) Consumer's surplus without apology, American Economic Review, 66, 589-597. 
${ }^{1}$ These are combinations of price and quantities of the good that enable the viability of the firm and are Pareto superior to any others. This concept was initially applied by Boiteux (1956) to the problem of choosing optimal taxes subject to a constraint on tax receipts. Later on, Baumol and Bradford (1970) extended it to the problem of choosing optimal prices subject to a budget constraint.

${ }^{2}$ His methodology uses a Marshallian demand function constructed with observations on prices and quantities demanded by consumers. With this type of demand function consumer surplus is well measured if income effects are not very significant.

${ }^{3}$ Until recently phone services in Portugal were provided by three companies: Marconi, CTT, and TLP. Marconi had the monopoly for international calls outside of Europe, TLP had the market for the two major cities of Lisbon and Porto and finally CTT, the largest company, covered the rest.

${ }^{4}$ Cabral's model derived efficiency and distribution optimal conditions for the telecommunications pricing. The Social Welfare function to be optimazed included distribution parameters.

${ }^{5}$ We assume that when we are analysing one market in particular, the transfer of income (utility) from consumers to producers is neutral.

${ }^{6}$ We know that the Telecommunications system offers a wide range of services: connection and use of telephone lines, private circuits rental, leased lines, transmission capacity, telex, and others. However, since data was not available, we were compelled to use a single measure of output, namely the real services receipts.

${ }^{7}$ See Greene, chapter 15 for details.

${ }^{8} \mathrm{Y}^{*}=\left(\mathrm{Y}^{\lambda}-1\right) / \lambda$ if $\lambda \neq 0$ or $\mathrm{Y}^{*}=\log \mathrm{Y}$ if $\lambda=0$

${ }^{9}$ See Kiss et al (1987) pag.318 for details.

${ }^{10}$ See Morris and Hay (1991), pag 581-2.

${ }^{11}$ It consists of a series of endogenous variables which are considered as a group because they bear a close relationship to each other. There is a relationship between the share equations, their sum is equal to one. In such a case the sum of the disturbances must be zero and ordinary least-squares estimation is not proper.

${ }^{12}$ The results of the iterative Zellner's technique are maximum likelihood estimates when the variance-covariance matrix converges.

${ }^{13}$ As Gabel et al (1993) did, we assume that access charges are subsumed into the usage charges.

${ }^{14}$ As explained by Cabral (1990) 
TABLE I-Parameter estimates for the Translog Cost Function

\begin{tabular}{|c|c|c|}
\hline Parameter & Estimate & T-Statistic \\
\hline CONSTANT (a) & $-0,026507$ & $-1,15951$ \\
\hline CAPITAL (b1) & $0,615483^{*}$ & 33,7541 \\
\hline LABOUR (b2) & $0,281289^{*}$ & 17,2066 \\
\hline MATERIALS (b3) & $0,103228^{*}$ & 13,9005 \\
\hline TECHNICAL PROGRESS (d1) & $-1,05368^{*}$ & $-4,68522$ \\
\hline OUTPUT (a1) & $0,542776^{*}$ & 4,74830 \\
\hline BOX COX (lam) & 0,00500375 & 0,024265 \\
\hline OUTPUT $^{2}(\mathrm{a} 11)$ & 0,618387 & 1,07128 \\
\hline CAPITAL-LABOUR (b12) & $-0,055008^{*}$ & $-3,12451$ \\
\hline CAPITAL-MATERIALS (b13) & $-0,029219^{*}$ & $-2,81316$ \\
\hline LABOUR-MATERIALS (b23) & $-0,048431$ & $-1,56420$ \\
\hline CAPITAL $^{2}$ (b11) & $0,084227^{*}$ & 4,41859 \\
\hline LABOUR $^{2}(\mathrm{~b} 22)$ & $0,10344^{*}$ & 3,52764 \\
\hline MATERIALS $^{2}$ (b33) & 0,07765 & 2,07277 \\
\hline TECHNICAL-PROGRESS $^{2}$ (d11) & $-0,649139$ & $-0,520401$ \\
\hline OUTPUT-CAPITAL (c11) & $0,120246^{*}$ & 2,1748 \\
\hline OUTPUT-LABOUR (c12) & $-0,129912^{*}$ & $-2,50505$ \\
\hline OUTPUT-MATERIALS (c13) & 0,00966575 & 0,47654 \\
\hline TECHNICAL-PROGRESS-OUTPUT (e11) & $-0,434802$ & $-0,534498$ \\
\hline TECHNICAL-PROGRESS-CAPITAL (f11) & $-0,146528$ & $-1,64083$ \\
\hline TECHNICAL-PROGRESS-LABOUR (f12) & 0,104301 & 1,24399 \\
\hline TECHNICAL-PROGRESS-MATERIALS & 0,042227 & 1,07297 \\
\hline
\end{tabular}


TABLE II: Elasticities Estimates

\begin{tabular}{lll}
\hline Elasticities & Estimate & T-Statistic \\
\hline Cost of output & 0,542776 & 4,7483 \\
Scale & 1,84238 & \\
\hline
\end{tabular}

